\title{
BMJ Open Management of acute venous thromboembolism among a cohort of patients discharged directly from the emergency department
}

\author{
Tammy J Bungard, ${ }^{1}$ Bruce Ritchie, ${ }^{2}$ Jennifer Bolt, ${ }^{3}$ William M Semchuk ${ }^{3}$
}

To cite: Bungard TJ, Ritchie B, Bolt J, et al. Management of acute venous thromboembolism among a cohort of patients discharged directly from the emergency department. BMJ Open 2018;8:e022064. doi:10.1136/ bmjopen-2018-022064

- Prepublication history for this paper is available online. To view these files, please visit the journal online (http://dx.doi. org/10.1136/bmjopen-2018022064).

Received 30 January 2018 Revised 7 June 2018 Accepted 28 August 2018
Check for updates

(C) Author(s) (or their employer(s)) 2018. Re-use permitted under CC BY-NC. No commercial re-use. See rights and permissions. Published by BMJ.

${ }^{1}$ Division of Cardiology, University of Alberta, Edmonton, Alberta, Canada

${ }^{2}$ Division of Hematology, University of Alberta, Edmonton, Alberta, Canada

${ }^{3}$ Pharmacy Services, Regina Qu'Appelle Health Region, Regina, Saskatchewan, Canada

Correspondence to

Dr Tammy J Bungard;

tammy.bungard@ualberta.ca

\section{ABSTRACT}

Objective To report the proportion of patients discharged directly from the emergency department (ED) on traditional therapy (parenteral anticoagulant \pm warfarin) or a direct oral anticoagulant (DOAC) for the management of acute venous thromboembolism (VTE).

Design Retrospective medical record review across four EDs in Edmonton, Alberta, two in Regina, Saskatchewan and three in rural Alberta.

Setting EDs from April 2014 through March 2015.

Participants Discharged directly from the ED with acute VTE. Patients were excluded if they had another indication for anticoagulants, were pregnant/breastfeeding or anticipated lifespan $<3$ months.

Primary and secondary outcome measures Primarily, the proportion of patients discharged directly from the ED that were prescribed traditional therapy or a DOAC, with comparisons between Edmonton, Regina and rural Alberta. Secondarily, therapy selection was compared based on deep vein thrombosis (DVT) versus pulmonary embolism (PE) and clot burden. Dosing of DOACs was assessed (when applicable) and follow-up in the community was compared.

Results After screening 1723 patients, 417 (24.2\%) were included with DVT and PE occurring in $65.5 \%$ and $34.5 \%$, respectively. More patients with PE were discharged from EDs in Edmonton (43\%) than Regina (7\%). Overall, the majority of patients were discharged on traditional therapy $(70.7 \%)$, with $27.8 \%$ receiving a DOAC. Uptake of DOAC use was highest in rural Alberta (53.3\%) compared with Edmonton (29.6\%) and Regina (12.1\%). DOACs were more commonly prescribed for PE (34.0\%) than DVT $(24.5 \%)$ $(p=0.04)$, proximal versus distal DVT $(28.4 \%$ and $17.3 \%$; $p<0.001$ ), and when prescribed were appropriately dosed in $79.3 \%$. Follow-up most commonly occurred via a VTE clinic in Edmonton or family physician in Regina and rural Alberta.

Conclusions Regional variation in discharging patients directly from the ED with PE is evident. While traditional therapy is most common, uptake of DOACs was modest given the timing of indication approval.

\section{INTRODUCTION}

Acute venous thromboembolism (VTE), including deep vein thrombosis (DVT) and pulmonary embolism (PE), is common,

\section{Strengths and limitations of this study}

- Our data set comprised of a large population representative of acute venous thromboembolism (VTE) discharged directly from emergency departments (EDs) and reflects practices over the span of a full year from Edmonton, Alberta, Regina, Saskatchewan and rural Alberta identified by reviewing each medical record.

- Individual chart audits enabled strict inclusion of acute VTE to accurately identify real-world practices.

- Inclusion of two urban centres (one with referral-based VTE outpatient clinics and one without) and rural Alberta (emergency department staffed by primary care physicians) offers insight into varying practices for the management of acute VTE.

- Assessing practice patterns via retrospective medical record review limited us to documentation within ED charting, thereby preventing us from identifying all a priori data elements for each patient (eg, weight) and not enabling us to assess outcomes once they left the ED.

impacting up to $5 \%$ of the population. ${ }^{1}$ After nearly 60 years with a parenteral anticoagulant \pm warfarin as the only option for the treatment of acute VTE, there are now four direct oral anticoagulants (DOACs) ${ }^{2-5}$ that have demonstrated non-inferiority for the prevention of recurrent VTE or VTE-related death and have major bleeding rates that are similar or less to that experienced with traditional care. ${ }^{6-12}$ In Canada, approval of the DOACs began in February 2012 with rivaroxaban for DVT and the PE indication followed in April of 2013; dabigatran came to market in June of 2014, apixaban in November of 2014 and, lastly, edoxaban in November of 2016. While the drug-dose sequence may complicate care delivery, the DOACs offer many practical advantages over traditional therapy (parenteral anticoagulation \pm warfarin). The DOACs do not require ongoing routine coagulation/laboratory testing, and 
apixaban and rivaroxaban have the added benefit of not requiring initial therapy with a parenteral anticoagulant. Most recent North American guidelines (2016) recommend the DOACs be used in preference to warfarin for the acute treatment of VTE in patients without cancer patients. ${ }^{3}$

Little, if any, data is available to assess physician practices pertaining to the use of DOACs for the acute management of VTE for patients discharged directly from the Emergency Department (ED). Moreover, it is not known if practices are similar between urban cities and rural sites. Given the ability of these agents to streamline care delivery, we hypothesised an early uptake of DOACs that was expected to be similar between urban cities yet greater in rural sites given the convenience of no routine laboratory monitoring and the ability to reach a smaller group of physicians for information dissemination.

\section{METHODS}

\section{Data sources}

Retrospective medical record reviews for each institution were performed to capture all data from the hospital-based chart. Data elements included patient demographics, type and severity of DVT or PE, anticoagulant prescribed at discharge and plan for follow-up in the community. Given this study spanned two urban cites and rural sites, three data extractors were required and all data were entered into a Research Electronic Data Capture (REDCap) database. ${ }^{13}$ The REDCap database was programmed for mandatory field entries, restrictions/limits for data fields and reports were run to allow quality assurance checks on all entered data. Missing data elements (weight, creatinine clearance $(\mathrm{Cr} \mathrm{Cl})$ ) were tracked, and are identified herein.

\section{Study setting}

This retrospective chart review encompassed hospitals representative of a collaboration of colleagues with similar interests and practices. These included the four largest hospitals in the Edmonton, Alberta area (University of Alberta Hospital, Royal Alexandra Hospital, Misericordia Hospital, Grey Nuns Hospital; population of 1328290 plus catchment of $\sim 500000),{ }^{14}$ the two academic hospitals in Regina, Saskatchewan (Regina General Hospital and Pasqua Hospital; population 230020 plus catchment area of 500000$)^{15}$ and three rural hospitals in Alberta (Wetaskiwin Hospital, population 12 621; Westlock Healthcare Centre, population 4823 and Athabasca Healthcare Centre, population 3000 ) in which the provision of emergency services is provided by primary care physicians with a private family medicine practices in the community. ${ }^{16-18}$ Data were combined and presented separately for each setting, namely Edmonton, Regina and rural Alberta, to enable comparisons between the two urban settings in different provinces with different health authorities (namely Edmonton and Regina) and the rural setting. For Edmonton, data were further broken down into academic sites (University of Alberta Hospital, Royal Alexandra Hospital) and community-based hospitals (Misericordia Hospital, Grey Nuns Hospital) given that two academic centres both have hospital-based ambulatory VTE clinics that accept referrals directly from the ED for patients newly diagnosed with VTE and it was hypothesised that anticoagulant therapies selected at discharge and planned follow-up patterns in the community may be different than that of the community hospitals. No other hospitals (cities) included in this study contained an ambulatory VTE clinic for referral of patients with newly diagnosed VTE.

\section{Patient population}

All patients discharged directly from the ED with an acute VTE (identified by ICD-10 codes I82 (DVT) or I26 (PE) with all subindices) from 1 April 2014 through 31 March 2015 were screened. Patients were excluded if they had atypical clot locations (eg, axillary/subclavian veins), another indication for therapeutic anticoagulation, an anticipated lifespan $<3$ months (documentation of palliation or prognosis), were not discharged alive, $<18$ years of age, were pregnant/breastfeeding or were admitted to the hospital.

\section{Outcomes}

Primarily, we assessed the proportion of patients discharged directly from the ED that were prescribed either traditional therapy (parenteral anticoagulant \pm warfarin) or a DOAC, with comparisons between Edmonton, Regina and rural Alberta. Within Edmonton, these data were further compared for academic and community-based hospitals. Secondarily, selection of anticoagulant therapies was compared in relation to DVT versus PE, based on $\mathrm{Cr} \mathrm{Cl}(<30,30-50$ and $>50 \mathrm{~mL} / \mathrm{min})$ as well as the burden of the clot. For DVT, clot burden was broken down based on being proximal (at or above the popliteal vein) or distal in the leg. For PE, presentation was assessed using two methods based on documentation at the point of PE diagnosis. First, we used the validated simplified Pulmonary Embolism Severity Indices (sPESI) of 0 or $\geq 1 .{ }^{19}{ }^{20}$ Second, we categorised them as massive (sustained hypotension (systolic $<90 \mathrm{~mm} \mathrm{Hg}$ for at least $15 \mathrm{~min})$, pulselessness, persistent profound bradycardia $(<40$ beats per minute with signs/symptoms of shock)), submassive (no hypotension yet the presence of right ventricular dysfunction evidenced by right ventricular dilation or myocardial ischaemia evidenced by elevation of biomarkers such as Brain Natureitc Peptide (BNP) or troponins) or low risk (normotensive, with no criteria previously stated). ${ }^{21}$ Lastly, we assessed the dosing for DOACs as per Health Canada-approved product monographs (when applicable) and with whom follow-up was to occur in the community.

While these data detail the management of acute VTE for those directly discharged from the ED, we also audited records for those hospitalised with acute VTE within these institutions. Our a priori evaluation plan 


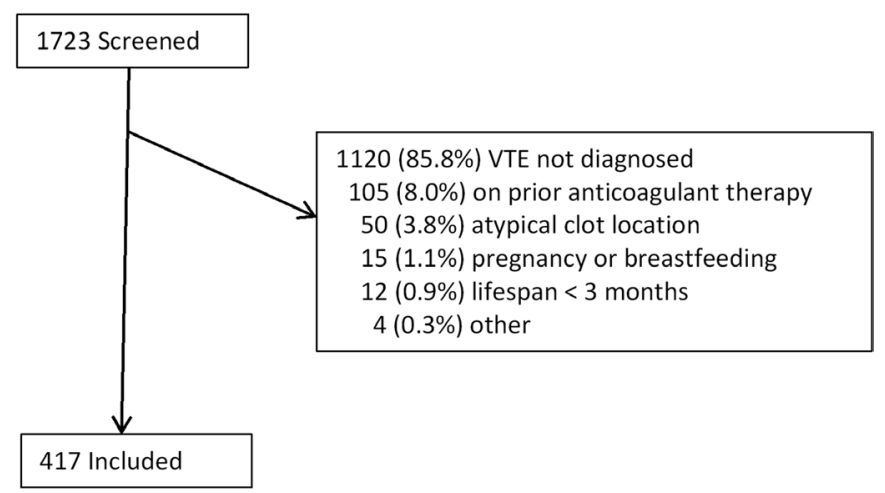

Figure 1 Patient flow. VTE, venous thromboembolism.

also encompassed an aggregate comparison of urban centres (Regina and Edmonton area only) among those discharged directly from the ED versus those hospitalised, ${ }^{22}$ as well as an evaluation of those hospitalised. ${ }^{23}$

\section{Patient and public involvement statement}

Patients and or the public were not involved in this study.

\section{Analysis}

Data analysis was performed at the Epidemiology Coordinating and Research Centre. All data within REDCap are at the University of Alberta, and are available to the principal investigator (TJB). No data sharing agreement is in place. Patients' characteristics were compared between sites using mean (SD) or median (IQR) as appropriate for the continuous data and proportions (\%) for categorical data. The $\chi^{2}$ test was used to compare discharge therapies between sites and different groups. Statistical analysis was performed using SAS V.9.4.

\section{RESULTS}

After screening 1723 patients, 417 (24.2\%) were included (figure 1). Most patients $(85.8 \%)$ were excluded as VTE was not diagnosed. Those in rural Alberta were older (68 years) and spent less time in the ED ( 2 hours) compared with Edmonton ( 56 years; 6 hours) and Regina (60 years; 6 hours) (table 1). Overall, the mean patient weight was $84 \mathrm{~kg}$, and the majority $(86.6 \%)$ had normal renal function. A greater proportion of patients discharged directly from the ED had PE in Edmonton (43.4\%), compared with Regina (7\%) or rural Alberta (20\%). The majority with PE (66.4\%) had a sPESI score of 0. Distal DVTs were much less common in the Edmonton sites (9.3\%) compared with Regina (40.3\%), potentially attributable to whole leg ultrasounds being performed in Regina, whereas proximal leg ultrasounds are standard of care in Alberta.

Among all sites, traditional therapy (parenteral anticoagulant \pm warfarin) was most commonly used (70.7\%), with DOACs being prescribed to $27.8 \%$ (table 2). Among the urban centres, Regina transitioned most patients to warfarin (75.9\%), while Edmonton sites more commonly discharged patients on parenteral anticoagulant therapy alone $(51.6 \%)$. Within Edmonton, the academic sites prescribed more parenteral therapy alone $(60.6 \%)$ than community-based sites $(41.0 \%)$ and less DOACs (20.6\% vs $40.3 \%$, respectively). Academic sites more commonly referred to VTE clinics $(80.6 \%$ and $33.8 \%)$, respectively (table 3). Primary care physicians in rural Alberta EDs had the highest rate of DOAC use (53.3\%), while Regina had the lowest $(12.1 \%)$. Of the DOACs, rivaroxaban was most frequently used $(95.7 \%)$ with the remainder being apixaban $(4.1 \%)$.

Overall, DOACs were used more commonly for PE $(34.0 \%)$ than DVT $(24.5 \%)$ ( $\mathrm{p}=0.04)$ with this use being driven by the Edmonton sites, as only a small numbers of patients ( $n=12)$ with PE were discharged from ED in rural Alberta or Regina. No difference was observed for DOAC use among those having a sPESI score of $0(35.8 \%)$ or score $\geq 1 \quad(31.3 \%) \quad(p=0.90)$. Similarly, no difference was observed for DOAC use based on clinical severity of low risk $(32.6 \%$; 42/129) versus submassive $(50.0 \%$; $7 / 15) \mathrm{PE}$ $(p=0.09)$ (data not shown). Overall, the prescription of a DOAC was more common for proximal DVTs (28.4\%) compared with distal DVTs $(17.3 \%) \quad(\mathrm{p}<0.001)$. Selection of a DOAC was not influenced by renal function, with $20 \%(\mathrm{n}=2 / 10), 23.5 \%(8 / 34)$ and $30.3 \%(86 / 284)$ receiving a DOAC with a $\mathrm{Cr} \mathrm{Cl}<30,30-50$ and $>50 \mathrm{~mL} /$ min, respectively.

Of those going home on a DOAC, $79.3 \%$ were prescribed a dosing regimen consistent with the Canadian product monographs, while $7.8 \%$ were prescribed a regimen not in alignment with monograph recommendations and $12.9 \%$ did not have a regimen documented in the chart (table 4). Of those with an identified discordant DOAC dose, the majority $(n=7 ; 77.8 \%)$ had incorrect drug-dose sequencing and two $(22.2 \%)$ were prescribed rivaroxaban despite having a $\mathrm{Cr} \mathrm{Cl}<30 \mathrm{~mL} / \mathrm{min}$.

On discharge from the ED, most patients in Edmonton were to follow up with the academic hospital-based VTE clinics $(59.2 \%)$, with this being more common at the academic sites (80.6\%) compared with the community-based sites not having VTE clinics $(33.8 \%)$. In rural Alberta and Regina, follow up with the family doctor was most common (53.3\% and $56.6 \%$, respectively).

\section{DISCUSSION}

In this cohort of patients discharged directly from ED with a VTE, traditional therapy with a parenteral anticoagulant \pm warfarin therapy was the most used strategy $(70.7 \%)$ while $27.8 \%$ of patients were discharged on a DOAC. Variation was observed across the sites with highest utilisation of traditional therapy in Regina $(75.9 \%)$ and DOAC in rural Alberta (53.3\%), while in Edmonton, the predominant strategy was a parenteral anticoagulant alone (51.6\%). Potential reasons for this variation include timing of the data collection in relation to Health Canada approval of the DOACs, availability of local outpatient VTE clinics (at the Edmonton-based academic sites but not Regina or rural Alberta) and specialisation of prescribers (EDs 
Table 1 Baseline characteristics

\begin{tabular}{|c|c|c|c|c|}
\hline & All & Edmonton & Rural Alberta & Regina \\
\hline Screened (N) & 1723 & 1371 & 185 & 167 \\
\hline Included (N, \%) & $417(24.2 \%)$ & $304(22.2 \%)$ & $30(16.2 \%)$ & $83(49.7 \%)$ \\
\hline Male $(\mathrm{N}, \%)$ & $220(52.8 \%)$ & $156(51.3 \%)$ & $14(46.7 \%)$ & $50(60.2 \%)$ \\
\hline Mean \pm SD age & $58.0 \pm 18.1$ & $56.3 \pm 18.5$ & $67.6 \pm 14.7$ & $60.4 \pm 16.4$ \\
\hline Hours in ED-median (range) & $6(4.0,8.5)$ & $6.3(4.4,9.0)$ & $2.2(1.2,3.5)$ & $6.0(4.5,8.3)$ \\
\hline Weight done $(\mathrm{N}, \%)^{\star}$ & 300 (71.9\%) & $204(67.1 \%)$ & $19(63.3 \%)$ & 77 (92.8\%) \\
\hline Weight (median) & $84(68.1,99.3)$ & $81.6(67.5,98.5)$ & $73.0(68.0,93.0)$ & $87.0(77.0,103.0)$ \\
\hline $\mathrm{Cr} \mathrm{Cl}(\mathrm{N}, \%)^{\star}$ & $328(78.7 \%)$ & $235(77.3 \%)$ & $22(73.3 \%)$ & $71(85.5 \%)$ \\
\hline$<30 \mathrm{~mL} / \mathrm{min}$ & $10(3.0 \%)$ & $7(3.0 \%)$ & $2(9.1 \%)$ & $1(1.4 \%)$ \\
\hline $30-49 \mathrm{~mL} / \mathrm{min}$ & $34(10.4 \%)$ & $21(8.9 \%)$ & $5(22.7 \%)$ & $8(11.3 \%)$ \\
\hline$>50 \mathrm{~mL} / \mathrm{min}$ & $284(86.6 \%)$ & $207(88.1 \%)$ & $15(68.2 \%)$ & $62(87.3 \%)$ \\
\hline \multicolumn{5}{|l|}{ VTE } \\
\hline DVT & $273(65.5 \%)$ & $172(56.6 \%)$ & $24(80.0 \%)$ & $77(92.8 \%)$ \\
\hline Distal & $52(19.0 \%)$ & $16(9.3 \%)$ & 7 (33.3\%) & $29(40.3 \%)$ \\
\hline Proximal† & $204(74.7 \%)$ & $147(85.5 \%)$ & $14(66.7 \%)$ & $43(59.7 \%)$ \\
\hline Not documented & $17(6.2 \%)$ & $9(5.2 \%)$ & $3(12.5 \%)$ & $5(6.5 \%)$ \\
\hline PE and PE+DVT $\neq$ & $144(34.5 \%)$ & $132(43.4 \%)$ & $6(20.0 \%)$ & $6(7.2 \%)$ \\
\hline \multicolumn{5}{|l|}{ PE-simplified PESI Score } \\
\hline 0 point & $96(66.6 \%)$ & $92(69.7 \%)$ & $1(16.7 \%)$ & $3(50.0 \%)$ \\
\hline$\geq 1$ points & $48(33.6 \%)$ & $40(30.3 \%)$ & $5(83.3 \%)$ & $3(50.0 \%)$ \\
\hline \multicolumn{5}{|l|}{ History of } \\
\hline Prior VTE & $92(22.1 \%)$ & $68(22.4 \%)$ & $6(20.0 \%)$ & $18(21.7 \%)$ \\
\hline Cancer & $64(15.3 \%)$ & $44(14.5 \%)$ & 7 (23.3\%) & $13(15.7 \%)$ \\
\hline Pulmonary disease & $41(9.8 \%)$ & $34(11.2 \%)$ & $2(6.7 \%)$ & $5(6.0 \%)$ \\
\hline Recent surgery & $30(7.2 \%)$ & $23(7.6 \%)$ & $1(3.3 \%)$ & $6(7.2 \%)$ \\
\hline
\end{tabular}

${ }^{*}$ Not all patients had weight and serum creatinine documented in the chart.

†Combined popliteal, femoral, common femoral and iliac.

$\ddagger P E$ and $\mathrm{PE}+\mathrm{DVT}$ are reported together.

$\mathrm{Cr} \mathrm{Cl}$, creatinine clearance; DVT, deep vein thrombosis; ED, emergency department; PE, pulmonary embolism; PESI, Pulmonary Embolism

Severity Index; VTE, venous thromboembolism.

in rural Alberta are staffed by primary care physicians while EDs in Edmonton and Regina are staffed by emergency medicine physicians). Further, the academic sites in Edmonton more frequently referred to an in-house VTE clinic compared with Edmonton-based community sites $(80.6 \%$ vs $33.8 \%)$ and predominantly used a parenteral anticoagulant strategy alone as compared with those that did not refer to VTE clinic $(60.6 \%$ vs $41.0 \%)$, deferring the decision on future oral therapy to the VTE clinic. These clinics advocate for the use of a DOAC, and hence our reported rates of DOAC use directly out of the ED are likely an underestimate of use in the Edmonton area.

Within the Edmonton area, $43.4 \%$ of the cohort of patients discharged from the ED with VTE had a PE, whereas only $7.2 \%$ of the cohort from Regina had a PE. Current guidelines suggest that patients with low-risk PE whose home circumstances are adequate should be treated at home or discharged early over a standard discharge that typically follows the first 5 days of treatment. ${ }^{12}$ Notably, with the Edmonton area, a small portion of patients were identified to have submassive PE $(\mathrm{n}=15,11.4 \%)$ while all patients in Regina $(n=6)$ and rural Alberta $(n=6)$ were deemed low risk. Clinician comfort and the ability to ensure prompt care in the community likely influenced these decisions. Among the academic Edmonton centres, $60 \%(n=45 / 75)$ with PE were discharged from the ED on a parenteral anticoagulant alone with the majority $(\mathrm{n}=40 / 45,89 \%)$ to be seen within the ambulatory VTE clinic for clinical assessment. In the community-based Edmonton hospitals, $33.3 \%$ (19/57) were discharged on a parenteral anticoagulant, with $57.9 \%(11 / 19)$ being referred to a VTE clinic or local intravenous clinic with nurse follow-up. Overall, regardless of the therapy at ED discharge, $66.7 \%$ (88/132) of patients in the Edmonton area being discharged with PE had clear documentation of follow-up within either a VTE or intravenous clinic, imparting comfort with ongoing care following ED discharge. This is affirmed by an audit of 175 patients 


\begin{tabular}{|c|c|c|c|c|c|}
\hline VTE specified & Total & Edmonton & Rural Alberta & Regina & $P$ values \\
\hline VTE (all combined) & & & & & $p<0.001$ \\
\hline Parenteral anticoagulant alone & $172(41.2 \%)$ & $157(51.6 \%)$ & $6(20.0 \%)$ & $9(10.8 \%)$ & \\
\hline Parenteral anticoagulant+warfarin & $123(29.5 \%)$ & $52(17.1)$ & $8(26.7 \%)$ & $63(75.9 \%)$ & \\
\hline DOAC & $116(27.8 \%)$ & $90(29.6 \%)$ & $16(53.3 \%)$ & $10(12.1 \%)$ & \\
\hline Rivaroxaban & $111(95.7 \%)$ & $87(96.7 \%)$ & $15(93.8 \%)$ & $9(90.0 \%)$ & \\
\hline Apixaban & $5(4.3 \%)$ & $3(3.3 \%)$ & $1(6.3 \%)$ & $1(10.0 \%)$ & \\
\hline Not documented & $6(1.4 \%)$ & $5(1.6 \%)$ & 0 & $1(1.2 \%)$ & \\
\hline $\mathrm{PE}$ and $\mathrm{PE}+\mathrm{DVT}$ & & & & & $\mathrm{p}=0.55$ \\
\hline Parenteral anticoagulant alone & $71(49.3 \%)$ & $64(48.5 \%)$ & $3(50.0 \%)$ & $4(66.7 \%)$ & \\
\hline Parenteral anticoagulant+warfarin & $20(13.9 \%)$ & $18(13.6 \%)$ & $2(33.3 \%)$ & 0 & \\
\hline DOAC & $49(34.0 \%)$ & $46(34.8 \%)$ & $1(16.7 \%)$ & $2(33.3 \%)$ & \\
\hline Rivaroxaban & $47(95.9 \%)$ & $44(95.7 \%)$ & $1(100.0 \%)$ & $2(100.0 \%)$ & \\
\hline Apixaban & $2(4.1 \%)$ & $2(4.3 \%)$ & 0 & 0 & \\
\hline Not documented & $4(2.8 \%)$ & $4(3.0 \%)$ & 0 & 0 & \\
\hline DVT alone & & & & & $p<0.001$ \\
\hline Parenteral anticoagulant alone & $101(36.9 \%)$ & $93(54.1 \%)$ & $3(12.5 \%)$ & $5(6.5 \%)$ & \\
\hline Parenteral anticoagulant+warfarin & $103(37.7 \%)$ & $34(19.8 \%)$ & $6(25.0 \%)$ & $63(81.8 \%)$ & \\
\hline DOAC & $67(24.5 \%)$ & $44(25.6 \%)$ & $15(62.5 \%)$ & $8(10.4 \%)$ & \\
\hline Rivaroxaban & $64(95.5 \%)$ & $43(97.7 \%)$ & $14(93.3 \%)$ & $7(87.7 \%)$ & \\
\hline Apixaban & $3(5.4 \%)$ & $1(2.3 \%)$ & $1(6.7 \%)$ & $1(12.5 \%)$ & \\
\hline Not documented & $2(0.7 \%)$ & $1(0.1 \%)$ & 0 & $1(1.3 \%)$ & \\
\hline \multicolumn{6}{|l|}{ Follow-up* } \\
\hline Family doctor & $124(26.8 \%)$ & $61(20.1 \%)$ & $16(53.3 \%)$ & $47(56.6 \%)$ & \\
\hline Return to ED & $16(3.4 \%)$ & $5(1.6 \%)$ & $7(23.3 \%)$ & $4(4.8 \%)$ & \\
\hline Specialist & $25(5.4 \%)$ & $13(4.3 \%)$ & $1(3.3 \%)$ & $11(13.3 \%)$ & \\
\hline VTE clinic & $186(40.2 \%)$ & $180(59.2 \%)$ & 0 & 0 & \\
\hline Anticoagulation clinic & $19(4.1 \%)$ & $3(1.0 \%)$ & $1(3.3 \%)$ & $15(18.1 \%)$ & \\
\hline Other & 55 (11.9\%) & 44 (14.5\%) & $1(3.3 \%)$ & 10 (12.0\%) & \\
\hline Not documented & $37(8.0 \%)$ & $23(7.6 \%)$ & $5(16.7 \%)$ & $9(10.8 \%)$ & \\
\hline
\end{tabular}

*Not mutually exclusive.

DOAC, direct oral anticoagulant; DVT, deep vein thrombosis; ED, emergency department; PE, pulmonary embolism; VTE, venous thromboembolism.

with PE within Kaiser Permanente in Northern California wherein $56(32.0 \%)$ patients were discharged within 24 hours of ED presentation. ${ }^{24}$ Notably, those at higher risk (PESI class III to V) received more prompt outpatient follow-up ( $81 \%$ within 3 days) relative to those deemed low risk (65\% within 3 days). In contrast, Regina does not have a local VTE clinic to offer timely, coordinated care to this population, and this may partially explain why only a small proportion of low-risk PE patients were discharged directly from the ED.

Practices in rural Alberta were different from that observed in the urban centres. The ED physicians in rural Alberta were, for the most part, the same family physicians seeing patients in the community setting. The follow-up plan with those in rural Alberta reflected this, being either with the family doctor $(53.3 \%)$ or to return to the ED (23.3\%). In rural Alberta, patients with DVT could only access ultrasonography at community-based diagnostic centres. Given this, it was common to have patients return to the ED for a parenteral anticoagulant daily until diagnostic confirmation could be performed in the community. Additionally, documentation in the rural ED was less complete in the form of confirming the diagnostic result given that patients would often follow up with their physician in the community, reflected by the lowest rate of inclusion (16.2\%). Lastly, two of the three rural sites staffed hospital pharmacists that sought additional training in anticoagulation management and had worked collaboratively within the local community. Use of DOACs was generally supported by these pharmacists, perhaps contributing to the higher rate of use in rural Alberta (53.3\%) versus the urban Edmonton sites 
Table 3 Edmonton comparison of academic with community-based hospitals

\begin{tabular}{|c|c|c|c|}
\hline VTE specified & Edmonton academic sites & $\begin{array}{l}\text { Edmonton community- } \\
\text { based sites }\end{array}$ & $P$ values \\
\hline VTE (all combined) & & & $p=0.0004$ \\
\hline Parenteral anticoagulant+warfarin & $28(17.0 \%)$ & $24(17.3 \%)$ & \\
\hline DOAC & $34(20.6 \%)$ & 56 (40.3\%) & \\
\hline Not documented & $3(1.8 \%)$ & $2(1.4 \%)$ & \\
\hline $\mathrm{PE}$ and $\mathrm{PE}+\mathrm{DVT}$ & & & $p=0.0039$ \\
\hline Parenteral anticoagulant alone & $45(60.0 \%)$ & $19(33.3 \%)$ & \\
\hline Parenteral anticoagulant+warfarin & $6(8.0 \%)$ & $12(21.1 \%)$ & \\
\hline Not documented & $3(4.0 \%)$ & $1(1.8 \%)$ & \\
\hline DVT alone & & & $p=0.0015$ \\
\hline Parenteral anticoagulant alone & $55(61.1 \%)$ & $38(46.3 \%)$ & \\
\hline Parenteral anticoagulant+warfarin & $22(24.4 \%)$ & $12(14.6 \%)$ & \\
\hline DOAC & $13(14.4 \%)$ & $31(37.8 \%)$ & \\
\hline Rivaroxaban & $12(92.3 \%)$ & $31(100.0 \%)$ & \\
\hline Apixaban & $1(7.69)$ & 0 & \\
\hline Not documented & 0 & $1(1.2 \%)$ & \\
\hline Other & $8(4.9 \%)$ & $36(25.9 \%)$ & \\
\hline Not documented & $3(1.8 \%)$ & $20(14.4 \%)$ & \\
\hline
\end{tabular}

${ }^{*}$ Not mutually exclusive.

DOAC, direct oral anticoagulant; DVT, deep vein thrombosis; ED, emergency department; PE, pulmonary embolism; VTE, venous thromboembolism.

(29.6\%). Moreover, less laboratory testing with the use of the DOACs in a rural versus urban setting is advantageous given the distances needed to travel to laboratories.

While use of DOACs was modest in our study $(27.8 \%)$, it is notable only rivaroxaban had an indication for VTE in Canada during the entire duration of our audit (March 2014 to April 2015), and provincial drug remuneration was only in place for DVT (not PE) with rivaroxaban for the entire audit year. Rivaroxaban was the DOAC most commonly used $(95.7 \%)$, with a minority of patients prescribed apixaban $(4.3 \%)$. Relative to other literature reports for DOAC use for acute VTE, our rates are modest. ${ }^{25}{ }^{26} \mathrm{~A}$ single-centre evaluation of 256 patients admitted to the ED or hospital in Quebec, Canada with VTE from February to September 2013 reported $17.6 \%$ of patients were discharged on rivaroxaban. ${ }^{25} \mathrm{~A}$ study assessing use among 328 patients with $\mathrm{PE}$ in France reported an increase in DOAC use at discharge from the 2014 audit (23.2\%) to the 2015 audit (40.1\%). ${ }^{26}$

Of those having documented dosing of a DOAC at ED discharge in our study, the majority $(91.1 \%, 92 / 101)$ complied with that in the product monographs. Limited data are available for comparison. A small Australian audit of 39 patients receiving a DOAC for acute VTE reported $84.6 \%$ to be appropriately dosed.${ }^{27}$ In the larger, non-interventional study of rivaroxaban for DVT, among 2619 prescribed rivaroxaban, $93.7 \%$ received the correct initial dosing of rivaroxaban $15 \mathrm{mg}$ two times per day. ${ }^{28} \mathrm{As}$ DOAC therapy and therapy options are likely to expand, it is imperative that drug-dose regimens are appropriately prescribed for this indication. 
Table 4 Dosing for DOACs on discharge from the emergency department

\begin{tabular}{|c|c|c|c|c|c|}
\hline DOAC regimen* & $\begin{array}{l}\text { Edmonton } \\
\text { academic sites } \\
n=34\end{array}$ & $\begin{array}{l}\text { Edmonton } \\
\text { community-based } \\
\text { sites } \\
n=56\end{array}$ & $\begin{array}{l}\text { Rural Alberta } \\
n=16\end{array}$ & Regina $n=10$ & Total $n=116$ \\
\hline Rivaroxaban & $\mathrm{n}=31(91.2 \%)$ & $\mathrm{n}=56(100 \%)$ & $n=15(93.8 \%)$ & $\mathrm{n}=9(90.0 \%)$ & $111(95.7 \%)$ \\
\hline $\begin{array}{l}15 \mathrm{mg} \text { two times per day, } \\
20 \mathrm{Q} \dagger\end{array}$ & $13(41.9 \%)$ & $38(67.9 \%)$ & $10(66.7 \%)$ & $8(88.9 \%)$ & $69(62.2 \%)$ \\
\hline $15 \mathrm{mg}$ two times per day $\dagger$ & $12(35.3 \%)$ & $7(12.5 \%)$ & $2(13.3 \%) \ddagger$ & $1(11.1 \%)$ & $22(19.8 \%)$ \\
\hline $\begin{array}{l}15 \mathrm{mg} \text { two times per day, } \\
15 Q D\end{array}$ & 0 & $1(1.8 \%)$ & 0 & 0 & $1(0.9 \%)$ \\
\hline $15 \mathrm{mg}$ QD & $1(3.2 \%)$ & 0 & 0 & 0 & $1(0.9 \%)$ \\
\hline $20 \mathrm{mg}$ QD & $1(3.2 \%)$ & 0 & 0 & 0 & $1(0.9 \%)$ \\
\hline Other & 0 & $1(1.8 \%)$ & $1(6.7 \%)$ & $\mathrm{n}=0$ & $2(1.8 \%)$ \\
\hline Not documented & $4(12.9 \%)$ & $9(16.1 \%)$ & $2(13.3 \%)$ & 0 & $15(13.5 \%)$ \\
\hline Apixaban & $n=3$ & $\mathrm{n}=0$ & $\mathrm{n}=1$ & $n=1$ & $5(4.3 \%)$ \\
\hline $\begin{array}{l}10 \mathrm{mg} \text { two times per day } \mathrm{x} \\
7 \text { days then } 5 \mathrm{mg} \text { two times } \\
\text { per day* }\end{array}$ & 2 & 0 & 1 & 0 & 3 \\
\hline $5 \mathrm{mg}$ two times per day & 1 & 0 & 0 & 1 & 2 \\
\hline Dosing as per PM & 27 (79.4\%) & 45 (80.4\%) & $11(68.8 \%)$ & $9(90 \%)$ & $92(79.3 \%)$ \\
\hline Dosing outside PM & $3(8.8 \%)$ & $2(3.6 \%)$ & $3(18.8 \%)$ & $1(10 \%)$ & $9(7.8 \%)$ \\
\hline Not documented & $4(11.8 \%)$ & 9 (16.1\%) & 2 (12.5\%) & 0 & 15 (12.9\%) \\
\hline
\end{tabular}

*Dosing as per product monographs: rivaroxaban $15 \mathrm{mg}$ two times per dayx 21 days then rivaroxaban $20 \mathrm{mg}$ daily; apixaban $10 \mathrm{mg}$ two times per dayx 7 days then apixaban $5 \mathrm{mg}$ two times per day; parenteral anticoagulant $\times$ 5-10 days followed by dabigatran $150 \mathrm{mg}$ two times per day. ${ }^{3-5}$

†Classified as dosing consistent with Health Canada-approved product monograph.

¥Both had creatinine clearance $<30 \mathrm{~mL} / \mathrm{min}$; hence were classified as discordant with Health Canada-approved product monograph.

$\mathrm{DOAC}$, direct oral anticoagulant; PM, product monograph.

\section{STRENGTHS AND LIMITATIONS}

To our knowledge, our data are the largest cohort of acute VTE patients managed directly out of EDs and represents a full year (1 April 2014 to 31 March 2015) of patients presenting with acute VTE at all institutions. We do acknowledge that rivaroxaban was the only DOAC with approval by Health Canada before this time interval, and our time interval reflects the early uptake of DOACs for the treatment of acute VTE. Approval of all other agents followed rivaroxaban, and practice patterns today may be different than identified during our evaluation interval, setting the stage for further assessment of uptake over time. Moreover, differing sample sizes between Edmonton, Regina and rural Alberta were achieved-in particular a low sample size in rural Alberta. Although small, we believe these data offer a reflective representation of these practice areas, given we spanned a full year of data and volumes are reflective of local (with catchment area) populations. Comparing these centres for the same time interval has provided us the opportunity to compare practices in different jurisdictions (eg, discharging of patients with PE directly from the ED, follow-up patterns and the influence of dedicated ambulatory VTE clinics following ED discharge) that offer healthcare system insight into clinician practices and institution use (namely comfort with discharging directly from the ED). We sought to identify practice patterns, and therefore conducted a retrospective medical record review. Given this design, we were able to accurately review individual charts, but were limited by the documentation available in the ED or hospital chart. Missing data elements (weight, serum creatinine) have been identified and reported, accordingly. Moreover, given the inclusion of two provinces and volume of sites, three data abstractors were necessary to conduct all the chart audits. To minimise bias and errors in coding, a key was created, teleconferences occurred and limits were programmed into REDCap for data elements with quality assurance checks performed for each site. Lastly, given our design and a priori identified outcomes, we were unable to follow patients after leaving the hospital, and therefore are unable to address outcomes/events during this time interval.

\section{CONCLUSION}

Overall, we observed traditional therapy (parenteral anticoagulant \pm warfarin) to be used most in our study $(70.7 \%)$, but report reasonable uptake of DOAC use (27.8\%), with more usage in Edmonton (29.6\%) than Regina $(12.1 \%)$ and the most use in rural Alberta 
(53.3\%). The Edmonton area discharged more patients directly from the ED with PE than the Regina area (43.4\% vs $7.2 \%$, respectively), with the majority of these patients being referred to a specialised VTE ambulatory clinic for follow-up in the community. Access to prompt ambulatory VTE follow-up appeared to influence both the comfort of discharging patients directly from the ED with $\mathrm{PE}$ as well as the therapy selected within the ED (most commonly a parenteral anticoagulant) - a finding that may offer insight into future resource allocation. As use of the DOACs is likely to increase for acute VTE management, it is paramount that prescribers implement the appropriate drug-dose sequences. Future evaluations to ensure appropriateness of DOAC use should ensue, as well as studies designed to follow patient outcomes after being discharged directly from the ED.

Contributors TJB drafted the initial protocol, participated in data acquisition, analysis and interpretation. She also drafted the initial manuscript and approved the final version to be published. BR critically reviewed the research protocol, contributed to the data interpretation, critically revised the manuscript and approved the final version to be published. JB participated in data acquisition, data analysis and interpretation, critically reviewed the manuscript and approved the final version. WS critically reviewed the research protocol, participated in data analysis and interpretation, critically reviewed the manuscript and approved the final version to be published. All authors are accountable for all aspects of the work.

Funding Funding was received from Pfizer Canada (via Dr. Bungard) in the form of an unrestricted grant.

Disclaimer The sponsor had no role in the protocol design, study conduct, analysis/interpretation of the findings or decision to publish.

Competing interests TJB has received honoraria for an advisory board from Boehringer Ingelheim, as well as honoraria for speaking from Bayer. TJB has received unrestricted grants from Pfizer and Leo Pharma Canada. BR has served on advisory boards, given sponsored lectures using his own slides and received travel expense remuneration for Bayer, Baxter, Beohringer-Ingelheim, CSL-Behring, Pfizer, Sanofi, Servier and Shire. In lieu of honoraria for these activities, the companies have given financial contributions to the University of Alberta. BR reports grants from Novo Nordisk, CSL-Behring and Baxter, all outside of this submitted work. JB has received speaker honoraria from Boehringer Ingleheim in the past two years. WS has received honoraria from Bayer, Pfizer, Bristol Myers Squibb and Boehringer Ingleheim. He has served as a consultant or on an Advisory Board for Bayer and Pfizer/Bristol Myers Squibb and he has received an unrestricted research grant from Pfizer.

Patient consent Not required.

Ethics approval Health Research Ethics Board-Health, University of Alberta (Pro00056384); Regina Qu'Appelle Health Region Ethics Board (REB 15-65).

Provenance and peer review Not commissioned; externally peer reviewed. Data sharing statement There is no data sharing agreement in place.

Open access This is an open access article distributed in accordance with the Creative Commons Attribution Non Commercial (CC BY-NC 4.0) license, which permits others to distribute, remix, adapt, build upon this work non-commercially, and license their derivative works on different terms, provided the original work is properly cited, appropriate credit is given, any changes made indicated, and the use is non-commercial. See: http://creativecommons.org/licenses/by-nc/4.0/.

\section{REFERENCES}

1. Wells PS, Forgie MA, Rodger MA. Treatment of venous thromboembolism. JAMA 2014;311:717-28.
2. Eliquis $\AA^{\circledR}$ Product Monograph. Pfizer Canada Inc, Kirkland, Quebec and Bristol-Myers Squibb Canada. Montreal, Quebec, 2015.

3. Lixiana $囚$ Product Monograph. Servier Canaeda. Laval, Quebec, 2016.

4. Pradaxa $₫$ Product Monograph. Boehringer Ingelheim Canada Ltd. Burlington, Ontario, 2015.

5. Xarelto $®$ Product Mongraph. Bayer Inc. Toronto, Ontario, 2015.

6. Bauersachs R, Berkowitz SD, Brenner B, et al. Oral rivaroxaban for symptomatic venous thromboembolism. N Engl J Med 2010;363:2499-510.

7. Büller HR, Prins $M H$, Lensin AW, et al. Oral rivaroxaban for the treatment of symptomatic pulmonary embolism. $N$ Engl J Med 2012;366:1287-97.

8. Schulman S, Kearon C, Kakkar AK, et al. Dabigatran versus warfarin in the treatment of acute venous thromboembolism. N Engl J Med 2009:361:2342-52

9. Schulman S, Kakkar AK, Goldhaber SZ, et al. Treatment of acute venous thromboembolism with dabigatran or warfarin and pooled analysis. Circulation 2014;129:764-72.

10. Agnelli G, Buller HR, Cohen A, et al. Oral apixaban for the treatment of acute venous thromboembolism. N Engl J Med 2013;369:799-808.

11. Büller HR, Décousus H, Grosso MA, et al. Edoxaban versus warfarin for the treatment of symptomatic venous thromboembolism. $N$ Engl J Med 2013;369:1406-15.

12. Kearon C, Akl EA, Ornelas J, et al. Antithrombotic therapy for VTE disease: CHEST guideline and expert panel report. Chest 2016;149:315-52.

13. Harris PA, Taylor R, Thielke R, et al. Research electronic data capture (REDCap)--a metadata-driven methodology and workflow process for providing translational research informatics support. J Biomed Inform 2009;42:377-81.

14. Population of Edmonton area. http://globalnews.ca/news/1824910/ edmonton-region-has-canadas-2nd-highest-population-growthstats-canada/ (accessed 31 Oct 2017).

15. Population of Regina. http://www.leaderpost.com/life/Regina+ population+cracks/9553267/story.html (accessed 31 Oct 2017).

16. Athabasca population. http://www.city-data.com/canada/AthabascaTown.html (accessed 31 Oct 2017)

17. Westlock population. http://www.city-data.com/canada/WestlockTown.html (accessed 31 May 2017).

18. Wetaskiwin population. https://www.wetaskiwin.ca/DocumentCenter/ View/1039 (accessed 31 Oct 2017).

19. Chan CM, Woods $C$, Shorr AF. The validation and reproducibility of the pulmonary embolism severity index. J Thromb Haemost 2010;8:1509-14.

20. Righini M, Roy PM, Meyer G, et al. The Simplified Pulmonary Embolism Severity Index (PESI): validation of a clinical prognostic model for pulmonary embolism. J Thromb Haemost 2011;9:2115-7.

21. Jaff MR, McMurtry MS, Archer SL, et al. Management of massive and submassive pulmonary embolism, iliofemoral deep vein thrombosis, and chronic thromboembolic pulmonary hypertension: a scientific statement from the American Heart Association. Circulation 2011;123:1788-830.

22. Bungard TJ, Ritchie B, Bolt J, et al. Anticoagulant therapies for acute venous thromboembolism: a comparison between those discharged directly from the emergency department versus hospital in two Canadian cities. BMJ Open 2018;0:e022063.

23. Bungard TJ, Ritchie B, Bolt J, et al. Anticoagulant therapies for acute venous thromboembolism among a cohort of patients discharged from Canadian urban and rural hospitals. BMJ Open 2018;0:e022065.

24. Vinson DR, Ballard DW, Huang J, et al. Timing of discharge follow-up for acute pulmonary embolism: retrospective cohort study. West $J$ Emerg Med 2015;16:55-61.

25. Dault R, Vanasse A, Blais L, et al. Patterns and predictors of use of anticoagulants for the treatment of venous thromboembolism following approval of rivaroxaban. Clin Appl Thromb Hemost 2016;22:765-71.

26. Masotti L, Vannucchi V, Poggi M, et al. Trends in length of hospital stay in acute pulmonary embolism over the years. What is changing in the era of direct oral anticoagulants? J Cardiovasc Med 2017:18:556-9.

27. Pattullo CS, Barras M, Tai B, et al. New oral anticoagulants: appropriateness of prescribing in real-world setting. Intern Med J 2016;46:812-8

28. Ageno W, Mantovani LG, Haas S, et al. Safety and effectiveness of oral rivaroxaban versus standard anticoagulation for the treatment of symptomatic deep-vein thrombosis (XALIA): an international, prospective, non-interventional study. Lancet Haematol 2016;3:e12-21. 